\title{
DIETARY POTASSIUM DOES NOT NEGATIVELY AFFECT BLOOD CALCIUM IN PERIPARTURIENT COWS FED PASTURE
}

\author{
J. R. Roche ${ }^{1}$, E.S. Kolver ${ }^{1}$, A. Roberts ${ }^{2}$ and J. Morton ${ }^{3}$ \\ ${ }^{1}$ Dexcel Ltd. (formerly Dairying Research Corporation), Hamilton, New Zealand, \\ ${ }^{2} \mathrm{AgResearch,}$ Ruakura, Hamilton, New Zealand, ${ }^{3} \mathrm{AgResearch}$, Invermay, New Zealand
}

The importance of optimising the balance of sodium, potassium, chlorine and sulphur (Dietary Cation Anion Difference; DCAD) in the diet of the dairy cow pre-calving is well recognised in total mixed ration feeding systems (Block, 1984). Goff and Horst (1997) found that dietary potassium is more important than dietary calcium in the prevention of parturient hypocalcaemia and claimed that previous work investigating the benefits of low calcium pre-calving diets may have been confounded by different potassium concentrations also. Pastures often contain in excess of $35 \mathrm{~g} \mathrm{~K} / \mathrm{kg} \mathrm{DM}$ and hence should be a major antagonist to calcium homeostasis. However, reducing the DCAD in pasture-based systems, through increased chlorine and sulphur concentration in the diet, did not increase plasma calcium pre- or post-calving (Roche, 1999). It was therefore hypothesised that a reduction in dietary potassium may increase plasma calcium concentration around calving.

Sixty-four grazing cows were randomly allocated to four groups of sixteen and offered pasture containing different concentrations of potassium. Mean pasture potassium concentrations were 35.2, 37.6, 41.2 and $42.2 \mathrm{~g} \mathrm{~K} / \mathrm{kg}$ DM for K1, K2, K3 and K4 treatments, respectively. As K concentration in pasture increased, the dietary cation-anion difference decreased linearly $(\mathrm{P}=0.06)$ in association with a decreased $\mathrm{Na}$ concentration $(\mathrm{P}<0.001)$ and an increased $\mathrm{Cl}$ concentration $(\mathrm{P}<0.001)$. This increasing $\mathrm{Cl}$ concentration supports the findings of Roche et al. (2000). Pasture Ca concentration declined linearly $(\mathrm{P}<0.05)$ as $\mathrm{K}$ concentration in pasture increased but $\mathrm{Mg}$ concentration was unaffected.

Plasma Ca concentrations at calving and the day following calving were unaffected by treatment but increased linearly $(\mathrm{P}<0.05)$ two days post-calving with increasing pasture $\mathrm{K}$ concentration. Plasma $\mathrm{Mg}$ around calving was not affected by dietary $\mathrm{K}$ concentration.

In summary, potassium concentration in pasture is positively related to chlorine concentration and negatively related to sodium and calcium concentration. Hence, increasing potassium concentration does not automatically increase DCAD. In the experiment reported here, an increased potassium concentration was associated with a lower DCAD. Dietary K concentration did not appear to influence the risk of hypocalcaemia around calving. Other factors, more important than potassium, appear to be influencing the occurrence of hypocalcaemia.

\section{References}

Block, E. (1984) Manipulating dietary anions and cations for pre-partum dairy cows to reduce the incidence of milk fever. Journal of Dairy Science. 67: 2939-2948.

Goff, J.P. and Horst, R.L. (1997) Effects of the addition of potassium or sodium, but not calcium, to prepartum rations on milk fever in dairy cows. Journal of Dairy Science. 80: 176-186.

Roche, J.R. (1999) Dietary Cation Anion Difference for pasture-fed cows. Ph.D. Dissertation. National University of Ireland.

Roche, J.R., Dalley, D., Moate, P., Grainger, C., O'Mara, F and Rath, M. (2000) Variations in the dietary cation anion difference and the acid-base balance of dairy cows on a pasture-based diet in south-eastern Australia. Grass and Forage Science. 55: 26-36. 